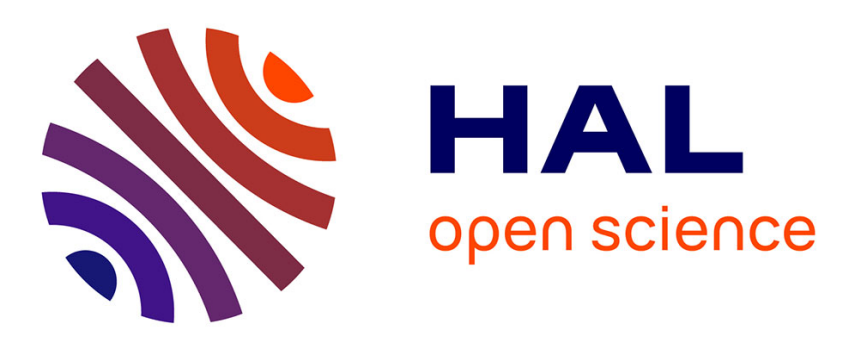

\title{
(ETHNO-)MEDICAL ETHICS IN GLOBALIZING CHINA: TRACING LOCAL KNOWLEDGE AND ADAPTATION OF BIOMEDICINE
}

Evelyne Micollier

\section{- To cite this version:}

Evelyne Micollier. (ETHNO-)MEDICAL ETHICS IN GLOBALIZING CHINA: TRACING LOCAL KNOWLEDGE AND ADAPTATION OF BIOMEDICINE. Journal International de Bioéthique, 2015, 26 (4), pp.101-116. 10.3917/jib.264.0099 . halshs-01643663

\section{HAL Id: halshs-01643663 \\ https://shs.hal.science/halshs-01643663}

Submitted on 21 Nov 2017

HAL is a multi-disciplinary open access archive for the deposit and dissemination of scientific research documents, whether they are published or not. The documents may come from teaching and research institutions in France or abroad, or from public or private research centers.
L'archive ouverte pluridisciplinaire HAL, est destinée au dépôt et à la diffusion de documents scientifiques de niveau recherche, publiés ou non, émanant des établissements d'enseignement et de recherche français ou étrangers, des laboratoires publics ou privés. 
Journal international de bioéthique et d'éthique des sciences, 2015, 26 (4): 97-112

International Journal of Bioethics and Sciences Ethics

Chapitre 5

(ETHNO-)MEDICAL ETHICS IN GLOBALIZING CHINA: TRACING LOCAL KNOWLEDGE AND ADAPTATION OF BIOMEDICINE

Dr. Evelyne MICOLLIER, PhD. Social Anthropology, MPhil. Chinese Studies, IRD

(French Research Institute for Development), UMI 233 TransVIHMI,

Cluster Local Cultures and Global Health, currently stationed at IRD Laos

Encounters between several medical traditions have led to a restructuring of the entire health system, including a transformation in medical ethics. Defining "new ethics" with both Chinese and international characteristics, is part of the ongoing knowledge production process: plural health ideas, practices and medical sciences develop within the broader framework of social and economic transition. Such transition simultaneously reveals and encourages China's influence and position in an era of globalization including in the technical and knowledge production domains: this process may unveil possibilities of an "alternative modernity" (Feenberg, 1995). Re-alignments in medical ethics in Reform China (post-1979) highlight a rather under-explored aspect of medical plurality enabling these ethics to be used as an analytical lens to provide information about social and

97

political issues. These latter are highlighted through an attempt at conceptual legiti- 
mizing, which has to be reasonably consensual to work as a tool for principles and practice in health education and interventions. The reality, scale and multi-layered implications of the transforming process can be traced in the guidelines for a new ethic: Nonetheless interacting bodies of medical knowledge and practice reflect anytime and anywhere cultural politics at work. An officially assessed failure in health management over two decades through a market-oriented reform prompted previously contained disapproving voices to express dissatisfaction in the academic arena: a number of medical professionals and social scientists argue that a solution might be to look back to previous medical ethical knowledge throughout Chinese history. Nonetheless medical ethics in the context of culture is a form of local knowledge (Christakis, 1992): subsequently it is worth further investigation and capturing the attention of the academic arena at an international level.

Further research is urgently needed as UNESCO programmes tackle the pressing and controversial issue of bioethics education with a focus on Asia (Calderbank, 2008): open debates and listening to voices from all stakeholders in Asian societies have been limited in the region so far while basic research and $R \& D$ in health sciences have promptly developed, and new (bio)technologies have become gradually available raising new ethical issues.

Two sets of principle formulation, one from Late Imperial China (Late Ming Era), the other from post-Mao China (1980s), were selected as case-studies mainly because they reflected at the time of their emergence an on-going radical change in society in the realm of health and medicine ${ }^{1}$. Therefore both sets of ethical principles unveil 
the process of legitimizing a "Chinese medicine" in a context of radical social and political change: such a process takes various conceptual and practical forms framed along the lines of the current dominant ideological system and constrained by socio-economic and political factors. Finally, a few points in regards to current ethical issues have been raised and discussed in globalizing China, which represents also a significant historical turn for China (2000s), will be highlighted in order to draw key concluding remarks.

1

Micollier (1995) explored local ethics as one singular aspect of therapeutic plurality:

part of this text is updated from this doctoral work. The broader study investigated therapeutic plurality in past and present China with a focus on the case of qigong practice. Qigong as a social practice related to health and religion stands as paradigmatic regarding the interacting bodies of knowledge and practice at $\mathrm{W}$. 98

\section{CASE-STUDY FROM LATE IMPERIAL CHINA}

The first case-study brings us back to the fifteenth century: contents indicate a support for the "Confucian doctors" (ruyi) who were in competition with other healers, in particular with "ordinary" practitioners (yongyi). The historical context should be informed here as the Ming dynasty period (roughly $15^{\text {th }}$-Early $17^{\text {th }}$ century A.D.), a turning point into the broader Late Imperial China period: during these centuries China experienced radical change and transition. It also meant significant transformatic in the body of health and medicine practice and knowledge through its systematization for the first time: in a breakthrough study, Scheid (2007) chose it as the initial historica 
phase to investigate Chinese medicine currents (1626- ) with a focus on the Menghe medicine. This medicine appears a posteriori as highly significant in discussions of medical ethics. In our example, the precepts contain ten deontological maxims designer for the physician (1) and ten moral maxims directed toward the patient (2)2. These maxims are significant because they reveal a Confucian-oriented ethical and theoretical approach. Firstly I will enumerate the guidelines designed for the physician, then those for the patient. Secondly I will briefly discuss the contents.

(1) The former set is as follows:

1. "In the first place they should adopt a disposition of humaneness ; this is a justific demand. They should make a very special effort to assist the people and to perfor far-reaching good deeds.

2. Secondly they should master the Confucian teachings. Confucian medical doctor: are a precious help at all times. Their principles are valuable and enlightening ; all the literature is open to them for consultation.

3. Thirdly they should be versed in the details of the pulse. It is necessary that they discern "interior" (li) from "exterior" (biao). If they but lower their fingers [on the pulse], everything will be clear to them. Thus they will be able to cure those who are gravely ill.

4. Fourthly they are to recognize the causes of disease. They have to be ready to spe about life and death. Only physicians who attain this stage are experts in their fie]

5. Fifthly they should know the types of climates and the macrocosmic phases, 
so as to understand the succession of the seasons. Accordingly they have to perform operations of replenishing [deficiencies] and reducing [over-abundances in the organism] with drugs of warm and cool temperature radiation, and to differentiate the treatments suitable at the time.

2and quoted by Unschuld (1979): 71-73.

Original text of the precepts: Gong Tingxian Wan bing hui qun, chapter 8: 34A-34B. Translated 99

6. Sixthlytheyshouldbefamiliarwiththedifferenttypesoftransportationchann els $[\ldots]$.

7. Seventhlytheyknowthepeculiaritiesofdrugsandcomposetheirprescription s corresponding to the individual diseases. If they do not distinguish between warm and cool [qualities of drugs] they may endanger life.

8. Eighthly they should be informed on the preparation of drugs [...].

9. Ninthly they should not bej ealous, neither should they let themselves be guided by other people's favor or disfavor [...].

10. Tenthly they should not esteem profits too highly, but instead cultivate humaneness and righteousness. Although we distinguish between the poor and the rich, there is but one type of drug".

(2) The maxims designed for the patient are as follows:

1. "In the first place they are to choose "enlightened physicians" (mingyi) and thereby receive help in their ailments. They have to be careful, because life and death follow each other closely.

2. Secondlytheyshouldbewillingtotakeremedies.Withtheirhelpevenaperson 
who has already fallen ill can yet get rid of his ailment [...].

3. Thirdly they should have the treatment started at an early stage [...].

4. Fourthly they should not have sexual intercourse, then their sufferings will cease by themselves [...].

5. Fifthly they should guard against any excitement and should be very careful in this respect. If a person is angry, the flames flare up in him. This creates great difficulties in bringing help and in checking [the disease].

6. Sixthly they should beware of wrong thoughts and take care of themselves in peace. If they avoid all troubles, the mind will find peace by itself.

7. Seventhly they eat and drink moderately. The preparation of food is to follow the rules. Too much is harmful to the mind ; satiation is difficult to digest.

8. Eighthly they should be concerned about their getting up and their getting rest. They have to reduce their social life: even slightly increased stress will drain the vitality.

9. Ninthly they should not believe in the heterodoxy [in medicine]. Such a belief is harmful. Alien principles are misleading; they deceive the people and make them uncertain.

100

10. Tenthly they should not fear expenses. What sense is there in economizing here ! I ask you, what is more precious, life or material goods?" 
In these maxims, theoretical moral principles and principles of health for life are in line with a Confucian-oriented world-view: theoretical principles refer to the system of correspondences and to the theory of the Five Phases and the Yin/ Yang in maxims (1) and (2) 8. Aspects of the theoretical and pharmacological knowledge required in traditional medicine are mentioned in maxims (1) 3, 5, 6, 7. Moral principles such as humanity (ren) predisposing benevolent behavior toward any other human being ; and justice and equity, namely righteousness (yi), are found respectively in maxims (1) 10 , and in maxim (1) 10. The principle of moderation referred to in maxim (2) 7 lies in the Confucian ideal of searching for the middle path: the middle (zhong) is associated with the balance leading to harmony. Lastly the control of emotions and of thought, respectively mentioned in maxims (2) 6 and (2) 7, contributes to the preservation and restoration of health.

\section{CASE-STUDY FROM THE REFORM ERA (POST-1979)}

The other example was elaborated in early post-Maoist China, a period of opening-up c ideas, on the side of the economic reform, which reflects a renewed encounter with Western philosophy. The following is based on the analysis of commentaries about a number of principles distinguishing current Chinese bioethics and traditional medical ethics (McGreal, 1991). These principles offer a glimpse of significant discussion on plural theory of knowledge applied in context and summarize the contents of 1980s medical ethics ${ }^{3}$.

(3) Among them, ten were identified as consensual: 
1. "Medical ethics is related to professional morality ; it seeks to identify the principles and rules to be used in guiding medical practice and in the resolution of moral issues concerning medical treatment $[\ldots]$.

2. Medical ethics is to be distinguished from medical morality in that the latter tend: to concentrate on the conduct of doctors, while the former may encompass the myriad of moral issues that arise in society as affected by the medical profession.

These are summarized by McGreal (1991) from a report of Dr Shi Dapu, then professor of ethics at Xi'an Medical University and vice-president of the university, who comments about them in two papers "Research in Bioethics and the Present state of Medical Ethics in China" and "The rise and Progress of Chinese Medical Ethics”. According to his account, National Conferences in Medical Ethics were held during the 1980s showing an official renewed interest for research in medical ethics and opening-up of ideas. The first of these conferences was held in 1981 in Shanghai.

101

3. Medical ethics is an ideology; it is of "universal nature," and its principles must relate to the whole society, not simply to the needs of the medical profession. Although medical ethics [in China as a "socialist" society] should incorporate traditional "humanism" [...], it should be broader in its objectives and applications.

4. Medical ethics is a science, but it must accept as fundamental categories such matters as "rights, duty, emotion, conscience, utility," and so forth.

5. Although the relationship between the doctor and the patient is no longer as close as it used to be, the new medical ethics requires that doctors be honest with their patients, that they emphasize a positive attitude toward service on the part of medical workers, and that they strive to unify the evaluations of therapeutic effects. 
6. In the evaluation of medical behaviour there are three kinds of utility one may consider - whether the behaviour is beneficial for the patient, whether it contributes to medical development, and whether it works to improve the human environment. However, questions of utility should be balanced against questions of moral justice. Conflicts of interest should be resolved by a rational consideration of these various factors so as to achieve unified judgement.

7. The central problems of present-day Chinese bioethics are those concerning euthanasia, the definition of death, the establishment of regulatory standards for artificial insemination, induced abortion, and procedures for handling congenitally deformed new-borns.

8. Modern medical ethics works to enlarge the conception of morality so as to include not only individual moral duties but also the duties of persons working collectively to improve the conditions and quality of human life.

9. Traditional medical ethics was greatly influenced by Confucianism, Buddhism, and Taoism, and it has historical limitations, but its positive contribution is the emphasis on equality of treatment so that the poor do not suffer from neglect or inadequate treatment. Modern medical ethics incorporates this respect for the individual person and this insistence on the equality of treatment.

10. A new medical ethics is needed to move beyond traditional conceptions of duty to a rational procedure of judgement whereby problems are resolved by attention to values, including those stemming from the public interest. Problems of treatment and problems of the distribution of services are amenable to a method of rational consideration that reconciles social utility with the concern for the individual and for equality of treatment" (McGreal 1991: 162-163). 
McGreal (1991) emphasizes the significance of the "socialist" ideological discourse in Chinese society. Indeed, maxims (3) 9 and 10 announce moral principles, which may be defined as "socialist", although not exclusively so. In addition to this point, the ten-point review suggests that it can be grasped in a more global perspective through the analysis of Western influence on the current Chinese medical ethics, rather than limiting its impact to a socialist character. Some principles tie in with ideas extensively discussed in Western philosophy: Principles (3) 1 and 2 are concerned with the difference between morality and ethics. Universality is found in Principle (3) 3. The issue of scientific relevance is addressed in Principles 4, 5 and 6 through the use of terms such as science, standards, and evaluation. Scientific rationale is referred to with the process of "rational evaluation" and "rational procedure of judgement". The main problems of Chinese medical ethics expressed in Principle (3) 7 are the same as those debated in Western biomedical ethics. The relationship between individual versus collective moral responsibility is mentioned in Principle (3) 8.

Principles (3) 9 and 10 are concerned with the relationship between tradition, modernization, and with what might be called Westernization or indeed globalization: tradition is considered an ineluctable basis for the process of modernization which itself postulates a kind of Westernization. Equality in medical treatment is a moral precept prescribed by Buddhism, Christianity, and Marxism. The preoccupation with adopting a rational procedure of standardized and normalized judgement is in line with the rationale of science: to this extent, it is rooted in Western ideas of knowledge modernization through the scientific paradigm.

Lieban (1990) studied the medical ethics of traditional and popular healers from a comparative perspective emphasizing the cultural differences but also the similarities beyond cultures, approaching biomedical ethics from an intercultural perspective. His account of the Chinese context is based on Unschuld's (1979) work on medical ethics in Imperial China. A key hypothesis is that similarities in medical ethics do exist in various cultural contexts independent of each other. He takes the case of biomedicine and of traditional medicine in imperial China as significant examples. He argues that both contexts share one principle and two important ethical issues: the principle of beneficence and assistance, the relationship between the two values is perceived as contradictory - profit generated by the practice of 
medicine versus the altruism necessary for the practice ; ethical issues concern the relationship between medical ethics and the process of professionalization.

As Lieban (1990: 233) building on Beauchamp \& Childress (1983) ${ }^{4}$ and Veatch (1981) put it, "Beneficence, defined here in broad terms as a duty to promote the

103

4beneficence, non maleficence and justice, for further explanations and a critical discussion on the

From the 1970s, four basic principles lie at the heart of Western bioethics, namely autonomy,

welfare of others, is a primary ethical principle of Western biomedicine, with roots that go back to the Hippocratic Oath". However rather than drawing too hasty a conclusion, the notion of "beneficence" should be looked at more closely: the meaning of the Western notion of "beneficence" may diverge from the meaning of "ren" (humaneness, humanity) in Chinese. According to Tung (1994: 490), reflecting the highest virtue, the character 仁 (ren) formed by "two" and "human" indicates that the body-self is part of a larger whole, more precisely of both another human being and/or of the natural environment'. Such a cosmological dimension is not present in the Western notion of "beneficence": the relationship of the human being to Nature is obviously very different in each context. In contrast, the principle of social ethics contained in the Chinese term is closer to the Western meaning. Chinese sources quoted by Unschuld (1979: 30, 52, 71) often mention the moral duty of helping others and of assisting sick people.

The first ethical issue identified earlier concerned the contradiction inherent in medical practice between making a profit and being altruistic: tension between self-interest and philanthropy has been analyzed as the key paradox in medicine (Pellegrino, 1985). The second ethical issue concerns medical ethics and the professionalization of medical practice. In the context of China (Unschuld, 1979) and in the context of Western civilization (Freidson, 1970), the codes of medical ethics are tools serving a corporation guaranteeing a moral use of medicine and assuming responsibility for medical resources. 
Ethno-ethics of medicine still needs to be explored: it "refers to moral tenets and problems of health care as they are conceived and reacted to by members of a society" (Lieban, 1990: 236). Even though most studies about medical ethics from an inter-cultural perspective focus on cultural differences, the consensus is compulsory because biomedicine has fully developed into global institutional medicine. However such consensus and subsequently homogeneity through a standardization and institutionalization process is only apparent and superficial. Therefore Kunstadter (1980) argues that behind the scenes introduction of Western medicine and the spreading of its ethics is the main explanatory factor for such apparent homogeneity. Taking the example of India, he shows how traditional ethical systems have been ignored by Westernized medical institutions. However biomedical ethics in non-Western countries inexorably experiences a process of adaptation to the norms and values of non-Western societies: the examples developed by Lieban (1990: 231) who traces the differences in neonatal care and health policies in Israel and in South Asia are significant.

roots and use of these values, see Beauchamp \&Childress (1983).

104

If biomedical perspectives conflict with local norms and values as is the case, for instar in a number of African countries regarding the practice of excision (Gallo 1986 ; Grüenbaum 1982), serious ethical issues emerge which need to be discussed and negotiated in context. From the field of health education to research and development sectors, biomedicine is always adjusted in context: such a localization process generate discussion and tensions regarding ideas (knowledge at work and its production) and practice (clinical, care, healing aspects, research) 5 including of course in the field of eth At this juncture, let us return to the Chinese situation with recently discussed ethicsrelated issues, namely informed consent, confidentiality, research ethics, and health 
reform guidelines with a focus on the patient-healer relationship.

\section{A FEW CRITICAL VIEWS FROM CONTEMPORARY DISCUSSIONS IN CHINA (2000S):}

\section{FROM RESEARCH ETHICS TO THE NEW HEALTH REFORM 6}

As is the case in many countries, family decision-making is the normative way of deali] has been recognized and recommended within the framework of the national medical e1 affected by a distressful situation, all members perceive themselves as sick and the mos effectively puts the others at risk: from this insider's view, the observer can understand and is made collectively. This attitude and concept question the value of confidentiality consent procedure. Confidentiality along with privacy are fundamental values in the $\mathrm{W}$, and a clear distinction between the private and public sphere. I will recall here that the r for informed content and the very idea of informed consent brings us back to the roots c namely the Nuremberg Code, the 1970s Bellemont report and North-American rules. 52011a.

6

This part is based on a research conducted from 2006 to 2011 by E. Micollier from IRD, UMI 233 (formerly UMR 145, IRD-University of Montpellier I) in partnership with PUMC/CAMS (Peking Union Medical College/Chinese Academy of Medical Sciences), Center for Bioethics, Beijing, headed by Qiu Renzong and Zhai Xiaomei. E. Micollier was the scientific manager of the IRD-PUMC/CAMS program in Social Sciences, which included a line on research ethics in China. On such process, see among other works, Gobatto \&Lafaye 2007, Micollier 2007, Micollier 105

Another issue concerns international normative rules that have not been sufficiently contextualized: informed consent is required for any treatment intervention and tragic cases like the one cited by Zhai (2012: 29) and Xia (2012: 78)7 are not rare. This sectior briefly enumerates issues affecting research ethics 8 ."Therapeutic misconception" is the 
norm rather the exception among patients/people involved in the experiment process (Micollier, 2012) who cannot ascertain the difference between treatment and experimer Even categories of health personnel may not possess sufficient knowledge or informatir to make the distinction even though such awareness is required to evaluate the risks anc benefits for the patient. Regarding research policy and ethical governance, the development of (basic) HIV/AIDS medical research such as government-supported vaccine research is a controversial issue in China: while the HIV and AIDS epidemic is rapidly spreading into the general population, much still needs to be done with regards to operational clinical research, expanding treatment, testing and prevention ${ }^{9}$. Vaccine development, promoted by a number of national and international stakeholders and funded by public research institutions, was questioned among scholars, experts, policy makers and civic actors. This is especially the case since the results have been disappointing over the years and have shown no major breakthrough. Other questions of "ethical governance" concern the creation of ethics committees, biomedical research on human beings and on animals. For instance, social and cultural factors impacting the development of a framework for animal research ethics may be identified as follows: local conceptualization of animal/ life and its implications on knowledge production in life sciences need to be taken into account as well as the changing perceptions of animals as a symbolic category, involving relationships betwe human/animal/nature (environment) and their use. Transition from rural to urban societ , social mobilization of civic actors for animal and environmental protection, and the trans-nationalization and delocalization of biomedical research (clinical trials) and 
medical tourism (organ transplantation) in times of globalization raise new questions. Research contextualization in developing countries is an issue of concern: greater risk of "softer" legislation (principles) and loose implementation unveiling a big gap

7A pregnant woman had lost her life due to lack of health information and sufficient awareness on the part of her husband who refused to sign the informed consent. This situation happened in Beijing in 2007.

8 The following points were developed in Micollier, 2008, and Micollier, 2012.

9 For instance, more than $2 / 3$ of estimated people living with HIV were still not aware of their serological sta in the late 2000 s.

106

between practices and principles, the weaker voice of civic actors confronted by national/global economic interests and the structural specificities of social/political systems, as well as the economic constraints of vulnerable patients/research subjects du to poverty. All these factors strongly impact the quality of negotiations among stakeholders with regards to research ethics. Nonetheless much can be learnt from the Chinese case from the time the country opened up (post-1979) till its full-blown globalization (2000s).

Since the late 2000s, the health reform designed to extend basic health insurance coverc and curb market-oriented health-care, among other goals, is in progress. A few chronological points with regards to health-care management in China need to be recalled here: 
In the 1980s, a first round of reforms characterized by market-led deregulation and massive retrieval of the State in terms of funding and control was gradually implements systems had experienced drastic changes on the road to economic liberalization.

Raising health-care standards and reducing government financial burden through markt competition and rules were generally approved. Even though there was some improvement in terms of operational efficiency and health facility modernization and standardization, one downside with regards to public health was an increased burde on the shoulders of individuals: in 2005 significantly enough more than half of total health-care expenditure $(55,5 \%)$ was borne by the people ${ }^{10}$. In the 2000 s, Chinese society experienced a new round of reforms called "new health reform" following the assessment of the failed reform and voices raised against the current health-care system and its dysfunctions: a number of studies and heated debates revealed the importance $\mathrm{o}$ trust lying at the heart of patient-healer relationship, which had been badly damaged over the years. This situation signals a rising societal interest in a wide-spread quest for better values which often translates into a search into the past. Confucian values and their possible application in medical ethics once again capture public attention in rethinking ethical issues and help to nourish the on going discussion.

Why did a new health reform become unavoidable for the Chinese government, to be subsequently considered a priority in public policy change? In the 2000s health had become the first preoccupation of the Chinese population (Micollier, 2011): the people' voice through the wide-spread use of what appeared as a new common adage kanbing gui, kanbing nan (indeed how expensive and difficult it is to consult) became 
so loud that official actors could no longer ignore it. Many cases demonstrating the vulnerability and lack of trust of ordinary people (lao baixing)

${ }^{10}$ Jiankang bao (Health News), 2005. This publication is an organ of the Ministry of Health. 107

had been circulated through all sorts of media, with whole families being ruined by a disease affecting one of its members, and patients not being taken care of because they could not afford the exorbitant fees (Micollier, 2011b, Zhai, 2012). All these examples prompted a widespread discussion followed by a heated debate on trust and its high place as a value among Confucian virtues as shown in our historical sets of medical ethics rules.

Lack of trust is widely acknowledged and restoring it was urged in both the intersubjective patient-healer relationship and, on a broader scale, in the population at large and within the health personnel network of relationships, as well as within the larger framework of the health system. Heuristically most contributions of the authors from China (Qiu, Zhai, Xia, Hou \&Xiao) address these issues in a Special Issue of the International Journal of Bioethics and Sciences Ethics concerning "Ethics-related issue in hospitals. French and Chinese situation compared" published in 2012.

Hou \& Xiao (2012: 88) assess the diversification of moral precepts and other priorities for medical practice and knowledge, which have recently developed into medical scien : "Efficiency, profit-maximization, and rationality have gradually replaced the pursuit c collective interests and egalitarianism in communist China, and traditional medical ethi 
governed by Confucianism has been substituted by professional ethics which are not that different from those in advanced Western industrial societies. The DPR (doctorpatient relationship) has thus become more rational-instrumental than relational". All these authors call for an overall change in attitude in the health sector. Quoting the exemplary behavior and ethical stance of some ancient Chinese physicians, Zhai (2012. wishes a return to medicine as a profession rather than a business following a convincir demonstration that medicine had gradually become a big business for health personnel since the implementation of the market-oriented reform in the 1980s. Qiu (2012: 18-19. addressed the issue by evaluating the ongoing changes over the past twenty years: the reform was recognized by the very powerful Chinese State Council as "basically unsuccessful" through the voice of the Center for Development Research ${ }^{11}$. Qiu highlig of the 1980s' reform process and from his analysis, voiced the need for renewed interes in Confucian style values of trust (Qiu, 2008) coming from the population at large: a ve common complaint was that the art of "ren" (humaneness, also known as humanism th Chinese way) had been transformed into the art of making money (Qiu, 2012: 18). Interestingly enough, while more than $90 \%$ of the population at large acknowledged the failure of the reform by strongly disapproving it, in contrast more than $90 \%$ of health-care professionals interrogated were very satisfied with it (He, 2005 quoted by Qiu, 2012: 19).

11September, 15, $2011 \mathrm{http}: / /$ www.drc.gov.cn/report.asp?t=report\&y=2005

The Evaluation and Recommendations of Healthcare Sector Reform, July 2005, retrieved 108 
Zhai (2012) concluded that, while medicine had become a big business, the goals and management of medical services need to be changed to restore people's trust in what hi turned into a highly damaged patient-healer relationship. Cases of aggression, attacks targeting health-care personnel, of personnel wearing helmets to protect themselves, ha become common in the 2000s ${ }^{12}$. The sociologist Xia (2012) gathered official data from surveys conducted in the 2000s in Shanghai, Beijing and in Hunan Province showing a consistently badly damaged therapeutic relationship: the number of incidents, medical malpractice, medical disputes, and medical staff being orally insulted or physically beat increased dramatically. Results from the Fourth National Health Service Survey completed in 2008 indicated that more than one in five of the medical staff surveyed ha endured oral insults, almost one per cent violence and close to six per cent threats, either orally or through mailed letters (Xia, 2012: 79).

Xia, Zhai, Qiu and Hou \& Xiao all focused on an increased/newly emerged "unbalance position of negotiation" (Xia, 2012), or on the asymmetric power relationship (Zhai, 2012) between doctors and patients as a key factor explaining why the relationsh had undergone such a dramatic change. Interestingly enough, this point is what the Nuremberg Code (1947) elaborated by a post-World War II U.S. Military Court aimed initially change, namely that reducing the power imbalance between medical staff, institutions, and the patient suggests, in a more egalitarian power-relation model, increasing the decision-making power of the patient who is intrinsically recognized as vulnerable. This is how and why the procedure of informed consent, "une capacité léga totale à consentir" (a complete legal capacity to consent), was created and from then or 
strongly recommended. "Complete legal capacity" of the individual means that the two parties are equal: subsequently in order to facilitate the analysis of risks and benefits fo: the individual concerned, sufficient and detailed information concerning the medical service should be provided (Ambroselli, 1994: 106). Following a Foucaldian reading (Foucault, 1976), the process consists in decreasing the "bio-political" power of the medical actors acting through a form of "governmentality" on bodies and individuals, in other words a subtle way to control one's body-selves.

\section{CONCLUSION}

A process of revitalization of historical medical ethics in the context of broader cultural kit repertoire change (increased interest for tradition, patrimony, both material and immaterial, knowledge, social ethics, etc.) is currently at work in China.

${ }^{12}$ For the report of a few significant cases, see Xia (2012): 78-79.

109

The 2000s was a period of renewed interest for Chinese traditional and popular knowledge, know-how and practice with a focus on both material and immaterial patrimony, and on norms and rules including social ethics for example.

The impact of such a revitalizing process regarding both knowledge and practice in China, has been visible on an international scale through increasing Chinese soft-power and the blossoming of Confucian Institutes which are seen as the best tool for this. In a broader perspective such influence has contributed to reshape East-West exchanges. Asian ideas make their way among peoples, institutions, and states in Western countries and to a certain extent on a global scale through a whole range of healing practices. Which practices, techniques and ideas from Western societies and their health-care systems are ready to be accepted and integrated, and how and why 
this could be done need to be investigated on a case by case basis. Nonetheless more or less "integrated" or "integrating" health-care systems, borrowing from other medical traditions as complementary care to biomedicine, are emerging. This trend is widely and more consensually accepted in preventive medicine, occupational and rehabilitation medicine, well-being and corporal techniques, pain management and palliative care. In contrast, it is still very limited in the field of ethics. Questions of ethical governance in this context should be raised in times of globalization and local voices from other ethics traditions should be heard so as to negotiate new rules (other rules) of ethical governance and not be trapped once again in an ethno-centrist view. They may help to design more implementable transnational ethics and thereby favour a situation of "win-win" encounters from the East to the West and from the South to the South.

\section{REFERENCES}

Ambroselli, C. 1994 L'éthique médicale, Paris, PUF.Beauchamp, T.L. \&Childress, J.F. 1983 Principles of Biomedical Ethics, New-York, Oxford University Press.

Calderbank, D. Chief Ed. 2008 Asia-Pacific Perspectives on Bioethics Education, Bangkok, UNESCO Asia and Pacific Regional Bureau for Education, 203 p.

Christakis, N.A. 1992 Ethics are local: engaging cross-cultural variation in the ethics for clinical research, Social Sciences and Medicine 35(9): 1079-1091.

Feenberg, A. 1995 Alternative Modernity. The Technical Turn in Philosophy and Social Theory, Berkeley\& L.A., University of California Press.

Foucault, M. 1976 Histoire de la sexualité, Tome 1, Paris, Gallimard.

110

Freidson, E. 1970 Profession of Medicine: A Study of the Sociology of Applied Knowledge, New-York, Harper and Row.

Gallo, P.G. 1986 Views of Future Health Workers in Somalia on Female Circumcision, Medical Anthropology Quarterly 17: 71-73

Gobatto I.\& Lafaye F. 2007 De l'Art d'accommoder le modèle biomédical ou comment rendre "convenables" et "recevables" des protocoles de prévention à Abidjan (Côte 
d'Ivoire), Sciences Sociales et Santé 25(3) : 5-29.

Gong, Tingxian 1925 Wan bing hui qun (chapter 8: 34A-34B), Shanghai Dacheng Shuju.

Grüenbaum E. 1982 The Movement Against Clitoridectomy and Infibulation in Sudan: Public Health Policy and the Women's Movement, Medical Anthropology Newsletter 13: 4-12.

He, T.Q. 2005 Two types of satisfaction degree, Jiankang bao (Health News), September 1: 4 .

Hou Xiaoshuo \&Xiao Ling 2012 An analysis of the changing doctor-patient relationship in China, International Journal of Bioethics (Journal International de Bioéthique) 23(2): 83-94.

Jiankang bao (Health News), July 1, 2005.Kunstadter, P. 1980 Medical Ethics in CrossCultural and Multi-Cultural Perspective, Social Science and Medicine 14B: 289-296

Lieban, R.W. 1990 Medical Anthropology and the Comparative Study of Medical Ethics in: Weisz G. ed. Social Science Perspective on Medical Ethics, Dordrecht, Kluwer Academic Publishers: 221-239.

McGreal, I.P. 1991 The new dimensions of Chinese Medical Ethics, Journal of Chinese Philosophy 18: 161-168.

Micollier, E. 1995 Un aspect de la pluralité médicale en Chine populaire : les pratiques de qigong. Dimension thérapeutique, dimension sociale, PhD. Dissertation in Social Anthropology, University of Aix-Marseille, 547 p.

Micollier, E. 2007 Facettes de la recherche médicale et de la gestion du VIH-sida dans le système de santé chinois : un autre exemple d'adaptation locale de la biomédecine, Sciences Sociales et Santé 25(3) : 31-39.

Micollier, E. 2008 «Building up a framework for further research cooperation in bioethics », Third Sino-French Meeting on Bioethics, Wuhan, Huazhong University, Dept of Philosophy of Sciences, November 14-16.

Micollier, E. 2011a Un savoir thérapeutique hybride et mobile. Eclairage sur la recherche médicale en médecine chinoise en Chine aujourd'hui, in L. Pordié éd. "Savoirs thérapeutiques asiatiques et globalisation », Revue d'Anthropologie des Connaissances (5) $1: 41-70$.

111

Micollier, E. 2011b « Pourquoi une réforme du système de santé est-elle urgente? » dans 
F. Duléry éd Aujourd'hui la Chine, Montpellier, CNDP (Centre National de Documentation Pédagogique)-CRDP, SCEREN (Services Culture Editions pour l'Education Nationale), collection «Questions Ouvertes » : 88-91.

Micollier, E. 2012 Transcultural discussion in bioethics drawn from research experience in China: building up a theoretical and methodological framework for further research cooperation (in French), International Journal of Bioethics (Journal International de Bioéthique) 23(2): 105-116.

Pellegrino, E.D. 1985 The Virtuous Physician and the Ethics of Medicine, in E.E. Shelp ed. Virtue and Medicine, Dordrecht, D. Reidel: 237-255.

Scheid, V. 2007 Currents of Tradition in Chinese Medicine 1626-2006, Seattle, Eastland Press.

Tao, J. ed 2008 China: Bioethics, Trust, and the Challenge of the Market, New York, Springer.

Qiu, Renzong 2008 Confucius Trust, Market and Health Reform, in J. Tao ed. China: Bioethics, Trust, and the Challenge of the Market, New York, Springer.

Qiu, Renzong 2012 Healthcare sector reform and its influence on public hospitals in Mainland China, International Journal of Bioethics (Journal International de Bioéthique) 23(2): 17-24.

Tung, M.P.M. 1994 Symbolic Meanings of the Body in Chinese Culture and "Somatization", Culture, Medicine and Psychiatry 18(4): 483-492.

Veacht, R.M. 1981 A Theory of Medical Ethics, New-York, Basic Books.Unschuld, P.U. 1979 Medical Ethics in Imperial China: A Study in Historical

Anthropology, Berkeley\& L. A, University of California Press.Wang Ruotao \&Henderson G.E. 2008 Medical Research Ethics in China, The Lancet, published online Oct.20, 2 p.

Xia, Guomei 2012 Undue game of baseline principles: the physician-patient relationship from a bioethical perspective, International Journal of Bioethics (Journal International de Bioéthique) 23(2): 77-81.

Zhai, Xiaomei 2012 Medicine: Business or Profession? International Journal of Bioethics (Journal International de Bioéthique) 23(2): 25-32.

112 